El relato de viaje en el complejo expositivo del siglo XIX, a través del caso de los liliputienses aztecas: Máximo y Bartola

\title{
Eunice Hernández Gómez
}

\begin{abstract}
RESUMEN: En el complejo expositivo del siglo XIX, hubo un tipo de exhibición —ya fuera exposición o espectáculo— vinculado al relato de viaje: éste fue su punto de partida y justificación. Este artículo aborda cómo el vínculo entre el relato de viaje y los mecanismos de exhibición generaron actitudes textuales, discursos sobre la otredad y nociones sobre las culturas precolombinas en la imaginación histórica que favorecieron la recepción en Inglaterra del caso de Máximo y Bartola, dos niños con microcefalia que fueron exhibidos como los últimos descendientes de una raza desparecida de "aztecas".
\end{abstract}

Palabras clave: relato de viaje, exposición, imperialismo, Máximo y Bartola.

ABSTRACT: As part of the exhibitionary complex of the nineteenth century there was a type of display - exhibition or show - related with the travel writing: this was their starting point and justification. This article researches how the link between travel writing and the exhibitionary mechanisms generated a textual attitude, a discourses on the otherness and notions about the pre-Columbian cultures in the historical imagination that allowed the reception in England of the case of Máximo and Bartola, two children with microcephaly that were exhibited as the last descendants of a lost race of "Aztecs".

Key words: travel writing, exhibition, imperialism, Máximo y Bartola.

En el ámbito museístico del siglo XXI, la exposición y el espectáculo hacen referencia a realidades distintas; mientras la exposición es el principal sistema de comunicación del museo que permite una visualización explicativa, principalmente a través de la puesta en escena de objetos, de aquello que la institución adquiere, conserva, estudia y/o difunde (Desvallées y Mairesse, 2010: 36-37), el espectáculo se asocia a la industria del entretenimiento y a las actividades de diversión pública propias del circo, la feria o la televisión. De este modo, a la exposición se le otorga una función formativa y didáctica, mientras que la función del espectáculo se reduce al ocio y al esparcimiento. No obstante, 
ambas son formas de representación de lo social y por ende, ambas generan conocimiento y modos de entender la realidad, así como tienden a legitimar discursos de poder.

En el siglo XIX, la exposición y el espectáculo estuvieron vinculadas a lo que Tony Bennett denominó el complejo expositivo, es decir, el conjunto de instituciones, eventos y disciplinas encaminadas a "mostrar y narrar", o dicho de otro modo, a exhibir objetos y/o personas para transmitir valores y significados culturales con el objetivo de regular el comportamiento social (Bennett, 1995; 312).

A diferencia del sistema carcelario en donde el poder sobre el individuo se ejercía controlando y castigando, como propuso Michel Foucault en Vigilar y Castigar (1975), el complejo expositivo contribuyó a consolidar prácticas hegemónicas en un sentido gramsciano, a través de discursos narrativos, espacios de representación y disposiciones arquitectónicas que, en el caso del imperialismo inglés del siglo XIX, diseminaron la ideología del progreso y del proceso civilizatorio. En ese sentido, la exhibición de la otredad — principalmente a través de los llamados espectáculos de curiosidades, rarezas o maravillas humanas, pero también de exposiciones etnológicas y ferias internacionalesestuvo orientada a representar a una gama de culturas diferentes $-y$ en ocasiones de personas con malformaciones físicas - en un conjunto uniforme caracterizado por el atraso cultural o primitivismo, de manera que el progreso inglés fuera visible y aprehensible (Bennett, 1995:4056).

En esta discusión, se inserta el célebre caso de Máximo y Bartola, dos niños con microcefalia que fueron exhibidos como los últimos descendientes de una raza desparecida de "aztecas".

Desde su aparición en 1849 cuando Máximo y Bartola eran unos pequeños niños ${ }^{1}$ hasta la actualidad, el caso de los "liliputienses aztecas" ha sido estudiado desde diversos campos disciplinares: científicos de la época como el anatomista Richard Owen, el taxónomo Henri Louis Frédéric de Saussure, los psiquiatras Jules Baillarger y Rudolf Leubuscher, el antropólogo físico Paul Topinard, el naturista Ernest-Théodore Hamy y los médicos Paul Broca y Rudolf Virchow, realizaron toda clase de observaciones y mediciones para determinar su procedencia étnica, así como su estado físico y mental.

En épocas más recientes, el caso ha sido examinado desde los estudios victorianos (Altick, 1978; Aguirre, 2005 y Qureshi, 2011) para profundizar sobre el papel que jugaron las exhibiciones en el imperialismo inglés; desde los estudios culturales (Bludford, 1997) para abordar la influencia del circo en

1 Según las estimaciones del médico Warren Mason, uno de los primeros científicos en examinarlos en 1851, Máximo tenía entre 7 u 8 años y Bartola entre 4 y 6. (COMAS, 1968: 41). 
la cultura popular estadounidense y en el entrenamiento comercial; desde la antropología física para abordar el desarrollo histórico de la disciplina (Comas, 1968); desde la arqueología (Medina, 2011) para analizar la noción de "civilización antigua"; desde la sociología de la discapacidad (Bogdan, 1988) e incluso, desde la historia social de la fotografía (Bogdan, Elks, Knoll, 2012).

No obstante, pese a que existe una abundante bibliografía sobre el tema, poco se ha profundizado sobre la importancia que tuvieron los relatos de viaje tanto en el caso de Máximo y Bartola, como en las diversos mecanismos de exhibición ${ }^{2}$-ya sea exposición o espectáculo-que conformaron el complejo expositivo del siglo XIX.

El estudio del relato de viaje como género literario y como generador de construcciones discursivas sobre la otredad es relativamente reciente, en gran medida porque el relato de viaje, dada su “heterogeneidad estructural, estilística y temática", ofrece una "notable resistencia a una caracterización formal" como género (Colombi, 2010: 287-290). No obstante, Edward Said demostró cómo la idea de Oriente no es una realidad inerte sino una construcción discursiva fabricada por el orientalismo, presente en estudios académicos, relatos de viajes, obras literarias, y otros productos culturales que, más allá de sus propósitos, estuvieron impregnados de significación política, lo que contribuyó a reproducir y legitimar las prácticas hegemónicas del imperialismo estadounidense y europeo (Said, 1997).

De acuerdo a Said, estos textos sobre la otredad conforman ficciones de viaje capaces de construir configuraciones y representaciones sociales convincentes, las cuales, a su vez, generan una actitud textual, es decir, un conjunto de nociones para conocer e interpretar la realidad extranjera. El desconocimiento de una cultura, así como el éxito aparente de un texto favorecen la actitud textual, la cual no sólo genera conocimiento sino también construcciones discursivas sobre la otredad (Said, 1997: 135-137).

Precisamente, este artículo aborda cómo los relatos de viaje fungieron como punto de partida, fundamento y estrategia para dar veracidad a los mecanismos de exhibición sobre los aztecas en el siglo XIX inglés, así como para generar actitudes textuales. En específico, se analiza cómo la exposición Ancient México, inaugurada en 1824 en el Egyptian Hall, así como la publicación del relato de viajes Incidents of Travel in Central America, Chiapas and Yucatán (1841) del

2 Según Desvallées y Mairesse, el término exhibición para referirse a las exposiciones ha caído en desuso pues, a diferencia del inglés, adquiere un sentido peyorativo en el francés y porque fácilmente puede confundirse con otro tipo de exhibiciones como las deportivas o el exhibicionismo (Desvallées y Mairesse, 2010: 38). No obstante, en este artículo se usará palabra exhibición para referirse en términos generales al acto de "mostrar en público", ya sea que tome la forma de exposición de objetos o bien, de espectáculo humano. 
escritor y diplomático estadounidense John Lloyd Stephens (1805-1852), el cual contenía ilustraciones del explorador y dibujante inglés Frederick Catherwood (1799-1854) contribuyeron a generar nociones ${ }^{3}$ sobre lo azteca que facilitó la recepción del caso de Máximo y Bartola en Inglaterra durante el siglo XIX.

\section{The Aztec Show: el Caso de Máximo y Bartola}

Durante las cuatro décadas que se presentó The Aztec Show, como se le conoce al conjunto de espectáculos conformados por The aztec children (18511852) que se mostró en Boston y Nueva York; The Aztec Lilliputians (1853-1857) exhibido en Londres, Liverpool, París y otras ciudades europeas; y The Aztecs (1870-1890) cuando viajan como parte del Barnum \& Bailey Circus, Máximo y Bartola tuvieron al menos seis diferentes managers y fueron presentados a diversos tipos de audiencias: presidentes, monarcas y aristócratas, entre ellos el Presidente Fillmore de los Estados Unidos, la Reina Victoria y Napoleón III; especialistas y académicos como los ya mencionados; y público general (Medina, 2011:238; Illustrated Sporting and Theatrical News and Record of General and Domestic Intelligence, 1867).

Meses después de la primera aparición de Máximo y Bartola en Nueva York en 1849, The Aztec Show comenzó a vincularse con un relato de viaje, publicado en 1850, atribuido a Pedro Velásquez, cuyo largo título expresa las intenciones detrás del escrito: explicar y legitimar el origen mítico de los niños "aztecas".

De acuerdo a Memorias de una expedición llena de acontecimientos en América Central; que dio como resultado el descubrimiento de la ciudad idólatra de Iximaya en una región inesperada, así como la posesión de dos notables niños aztecas, descendientes y especímenes de una casta sacerdotal (ahora casi extinta) de antiguos aztecas fundadores de los templos en ruinas del país descrito por John L. Stevens y otros viajeros ${ }^{4}$, Máximo y Bartola fueron exhibidos primero como enanos por una persona que no conocía su "verdadero origen y raza", pero que dicho relato permitiría que fueran reconocidos como "especímenes" de una "absolutamente única y casi extinta raza de seres humanos que reclamaría la atención de los fisiólogos y de todos los hombres de ciencia"(Velásquez, 1850; 35).

Según el panfleto, Máximo y Bartola eran los descendientes de "una antigua y singular casta de sacerdotes llamada Kaanas" que supuestamente había

3 El término noción hace referencia simplemente a"la recepción y el reconocimiento de la idea de una realidad", a diferencia de la concepción que puede "ser la producción de realidad" (Ferrater Mora, 1994: 2567).

4 La traducción del título y de las frases citadas son mías. En el título original de la obra, el apellido de John L. Stevens aparece con "v", aunque se escribe con "ph", es decir, Stephens. 
migrado desde las Ilanuras asirias. Su lugar de origen, Iximaya, se describía como una ciudad precolombina, pero con muros al estilo egipcio y estatuas de los antiguos reyes de Siria que, según el panfleto, databan de antes de la fundación de Babilonia. Por otro lado, el relato de viaje explicaba que la peculiar fisonomía de Máximo y Bartola (cabeza pequeña, nariz prominente y baja estatura) se había conservado a causa de los matrimonios endogámicos, lo cual también explicaba su deficiencia mental (Velásquez, 1850; 16-31).

Al igual que casi todos los relatos de viaje del siglo XIX, la obra está escrita en primera persona, aunque el narrador combina su propia crónica de los hechos con el diario de viaje de un tal Pedro Velásquez, oriundo de San Salvador, quien supuestamente había participado en la expedición, junto al Sr. Huertis de Baltimore, un experto viajero que había visitado Egipto, Siria y Persia, y el Sr. Hammond, un ingeniero civil oriundo de Canadá. Tras su escape de Iximaya, donde habrían muerto el Sr. Harris y el Sr. Hammond, Pedro Velásquez había escrito de "memoria" su relato, lo que de manera implícita contribuía a explicar la ausencia de ciertos datos como la ubicación exacta de Iximaya, así como la perdida de los daguerrotipos que supuestamente se tomaron de la ciudad.

A pesar de que el verdadero autor de Memoir of an eventful expedition... permanece anónimo, mi hipótesis es que el célebre empresario del espectáculo Phineas Taylor Barnum (1810-1891) estuvo vinculado con la publicación de dicho relato de viaje, ya que una de las primeras imágenes (fig. 1) que contamos de Máximo y Bartolo, data también de 1850 y forma parte de una serie de litografías ligadas al Barnum's Gallery of Wonders (como se puede apreciar en la parte inferior), iniciada en 1848, fecha en la que aparece la primera litografía numerada del General Tom Thumb (1838-1883).

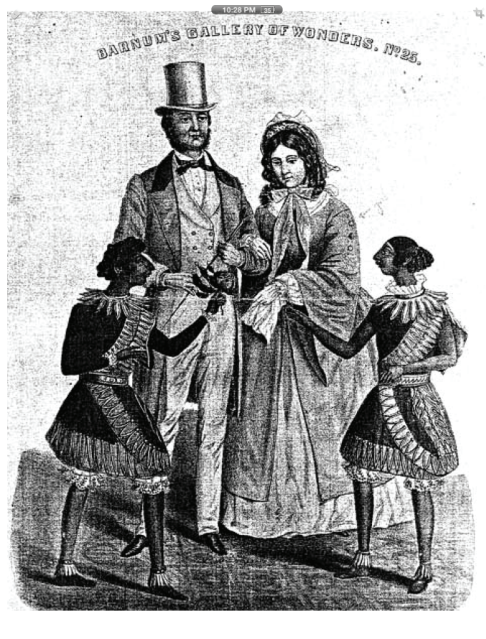

Fig. 1 
Pero más allá de la autoría, desde el punto de vista interno del relato se utilizaron varios recursos narrativos para darle verosimilitud. Por un lado, la escritura en primera persona reforzó lo que Philippe Lejeune llamó el pacto de autobiográfico, mecanismo por el cual existe en las narraciones autobiográficas un contrato implícito que permite a los lectores percibir el contenido como real (Lejeune, 1975). Por otro lado, el texto utilizó como punto de partida una anécdota, en la cual un cura de Santa Cruz del Quiché en Guatemala aseguraba que existía una ciudad mítica ocupada por indios en la misma condición en que se hallaban antes del descubrimiento de América, citada en el relato de viaje de Incidents of Travel in Central America, Chiapas and Yucatán (1841) de John Lloyd Stephens.

Incidents of Travel... se convirtió en un éxito literario y científico que contribuyó al desarrollo de la arqueología norteamericana y a los estudios sobre la civilización maya. En los diez años posteriores a su publicación, se realizaron 25 reediciones e incluso la obra fue catalogada por Edgar Allan Poe como el libro de viajes más importante de la época (Medina, 2011: 194).

Asimismo, las litografías de Catherwood (fig. 2) que acompañaron el relato de viaje de John Lloyd Stephens fueron reconocidas por su valor estético e histórico, lo que lo llevó a publicar en 1844 una versión más detallada y a color titulada Views of Ancient Monuments in Central America, Chiapas and Yucatán, cuyas ilustraciones fueron expuestas en instituciones como el Royal Institute of British Architects, el New York Historical Society, la National Academy of Design y el American Art Union.

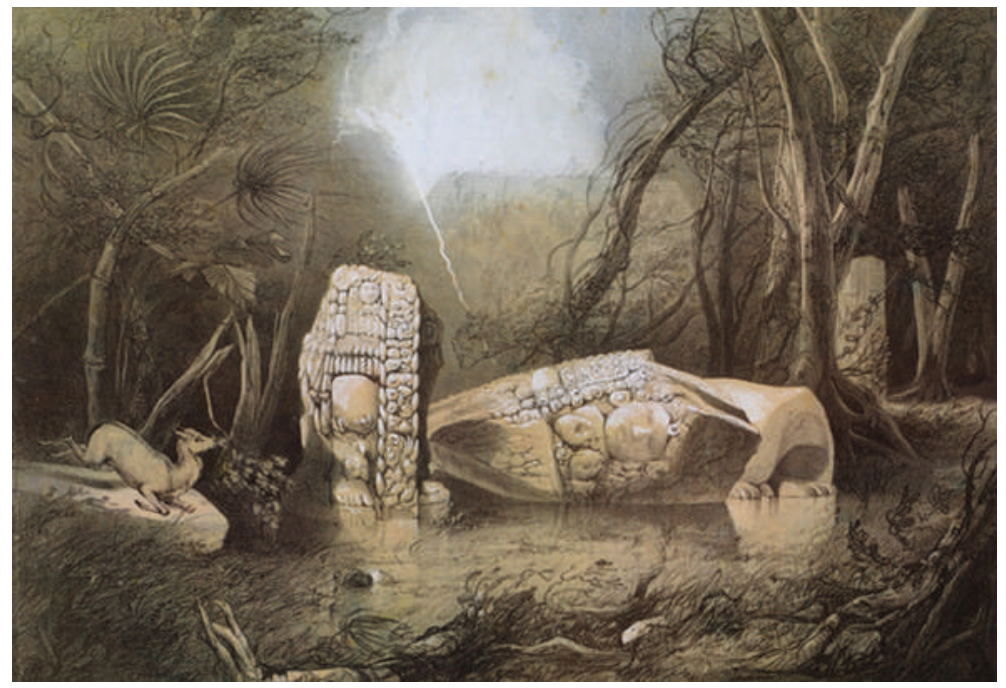

Fig. 2 
El parecido entre las ilustraciones de Catherwood y la fisonomía de Máximo y Bartola—similitud que se exponía en Memoir of an eventful expedition— también contribuyeron a darle credibilidad a la falsa teoría de su descendencia azteca, incluso cuando las estelas representadas por Catherwood correspondían a la cultura maya. Al respecto, hay que destacar que las exhibiciones de la época no emplearon el concepto de Mesoamérica y frecuentemente expusieron una gama de objetos de México y América Central dentro del mismo entorno, sin discriminación entre sus afiliaciones culturales (Medina, 2011;98).

El fenómeno de Máximo y Bartola, incluyendo el panfleto de su origen, nace en Estados Unidos, pero desde junio de 1853 llega a Inglaterra, donde causa furor: el 19 de junio son examinados por el anatomista Richard Owen, el 4 de julio son presentados en audiencia privada a la corte británica —a la cual asisten la reina Victoria y el príncipe Alberto- y el 6 de julio de ese año "fueron tema para una sesión especial en la Sociedad Etnológica de Londres donde R. Cull y Richard Owen presentaron importantes estudios al respecto" (Comas, 1968: 13).

¿Cómo podemos explicar tal recepción? Como apunta Aguirre, varios fueron los factores que contribuyeron a que los niños aztecas se convirtieran en un fenómeno cultural en Inglaterra: el surgimiento de la teoría racial, la medición como herramienta de investigación científica, la fundación de la Sociedad Etnológica de Londres en 1843, el interés de registrar razas "perdidas", la reciente investigación arqueológica en torno a México y Centroamérica tras el viaje de Stephens (Aguirre, 2003; 40-63) y la afluencia de viajeros ingleses a Latinoamérica como el viaje de William Bullock a México. Las razones son numerosas y todas están relacionadas entre sí, pero lo que interesa para fines de este artículo es remarcar la importancia que tuvo la exposición Ancient México para generar una actitud textual sobre lo que debería ser lo "azteca", noción que tras esta exposición —la primera en su tipo- se ligó al concepto de "civilización antigua" (Medina, 2011; 271).

\section{LOS MECANISMOS DE EXHIBICIÓN COMO GENERADORES DE ACTITUD TEXTUAL}

El viajero, naturalista y coleccionista William Bullock (ca.1770-1849) fundó su primer gabinete de curiosidades hacia 1799 primero en Sheffield y luego en Liverpool. En 1809 se mudó a Londres, donde contrató al arquitecto Peter Frederick Robinson (1776-1858) para diseñar el London Museum también conocido como el Egyptian Hall, debido a su fachada basada en el Templo de Hathor en Dendera, que lo convirtió en el primer edificio público de Londres influenciado por el estilo egipcio (Werner, 2003: 82-83). 
A pesar del éxito del Egyptian Hall, Bullock decidió vender su colección de historia natural en 1819 y pasó los años siguientes como subastador hasta que, en diciembre de 1822, se embarcó, junto a su hijo, rumbo a Veracruz. Llegó a México en enero de 1823, donde pasó varios meses recorriendo el país para recolectar objetos, esculturas y especímenes biológicos, como lo plasmó en su relato de viaje Six Months Residence and Travels in México, cuya primera edición publicada en 1824 se agotó en unos cuantos días (Costeloe, 2010: 1205), lo que deja entrever el interés que despertaba la ex colonia española, recién independizada, en los lectores ingleses.

Bullock regresó a Londres en 1824 con la intención de presentar una doble exposición sobre el México antiguo y moderno en el Egyptian Hall, recinto que se había convertido en una sala de exposiciones temporales que albergó exitosas muestras como la Tumba de Seti en 1821, descubierta, documentada y exhibida por Giovanni Battista Belzoni.

A diferencia de su colección de historia natural que estuvo organizada bajo la categorización binominal de Linneo (Pearce, 2007), Bullock buscó una disposición diferente para Ancient México basada en un acomodo narrativo. Como él mismo escribió en el catálogo de la muestra, el espacio "había sido habilitado para expresar la idea de un templo en México, donde se mostraban objetos relacionados con la religión antigua" (Bullock, 1824a; 30). Compuesta por al menos 44 piezas, expuestas sin vitrinas, en la exposición sobresalían cuatro reproducciones monumentales dispuestas en tres ejes: el "Ídolo de la Diosa de la Guerra", actualmente conocida como la Coatlicue; la "Piedra de los sacrificios", hoy identificada como la Piedra de Tízoc; el "Gran calendario de piedra", conocido como la Piedra del Sol y finalmente, la "Gran Serpiente" que, aunque no se identifica con ningún monolito, se trataba, según Bullock, de una reconstrucción inspirada en una escultura encontrada por él mismo en el claustro del Templo de Santo Domingo, en contra esquina del Palacio de la Inquisición (fig. 3).

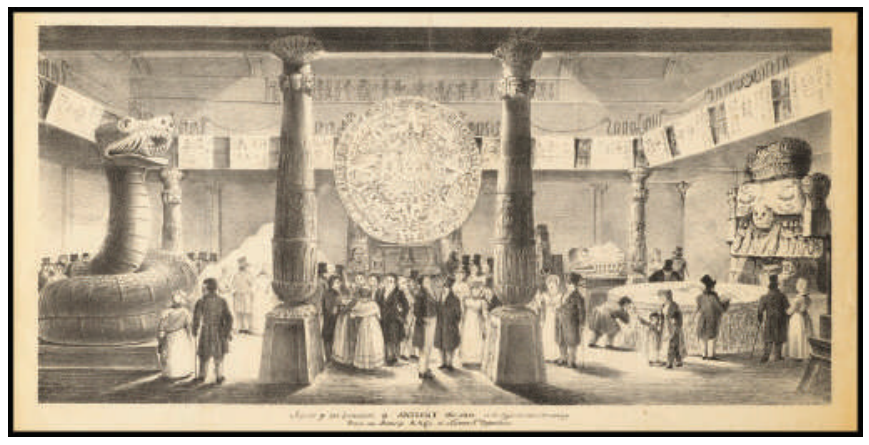

Fig. 3 
Además de la carga simbólica que implicó realizar la exposición en el Egyptian Hall, un espacio configurado como un templo egipcio, Bullock plasmó en el catálogo de la muestra su convicción de que las "antigüedades" de Méxicotales como las pirámides, la escritura jeroglífica y las esculturas en piedrapresentaban similitudes con las egipcias. Asimismo, sostuvo que culturas como las precolombinas, la budista y la hindú compartían deidades y piezas "monstruosas y sangrientas" por lo que podían haber tenido un mismo origen (Bullock, 1824a; 3).

Por otro lado, el catálogo daba peso al papel del testigo ocultar, por ejemplo, a las descripciones realizadas en las Cartas de Relación de Hernán Cortes y en las crónicas de Bernal Díaz del Castillo, las cuales —según Bullock-merecían más crédito que las explicaciones conjeturales de historiadores que nunca habían conocido el país (Bullock, 1824a: 6)5. Además, Bullock utilizó otras estrategias para darle veracidad a su exposición tales como: mostrar y hacer referencia a documentos históricos (entre ellos un mapa realizado por orden de Moctezuma y un manuscrito que ha sido identificado como el Códice Boturini o La Tira de la Peregrinación $n^{6}$ ); mostrar la procedencia de las piezas e incluso sugerir su función; indicar la ubicación donde fueron descubiertas, así como mencionar a quién pertenecían las piezas (Bullock, 1824a; Medina, 2011: 110). En cuanto a las reproducciones, insistió en que las copias exhibidas habían sido modeladas de acuerdo a las originales con el permiso del gobierno mexicano, el cual —en palabras del coleccionista inglés - "estaba ansioso de difundir el conocimiento de la América Española y cultivar una relación con Europa". (Bullock, 1824a: 5).

El viaje de Bullock se realizó en un periodo crucial para México pues la independencia todavía no era reconocida por España. Todo parece indicar que el viajero inglés entró en contacto con Lucas Alamán, quien tras la abdicación de Agustín de Iturbide en 1823, se desempeñó como Ministro del Interior y de Relaciones Exteriores, y a quien Bullock agradeció su apoyo en su relato de viaje. El vínculo resulta substancial si tomamos en cuenta tres factores: primero, que Lucas Alamán fue uno de los primeros políticos mexicanos que vio en la constitución británica un modelo para las leyes mexicanas y que fue el autor intelectual del proyecto de integración Pacto de Familia que buscaba fortalecer la presencia de Latinoamérica en el mundo (Andrews, 2011: 4-23).

5 Bullock se refería específicamente al historiador William Robertson (1721-1793), quien consideraba que los aztecas sólo habían conseguido un pequeño progreso más allá de las tribus salvajes.

6 Ambas piezas vienen descritas en el catálogo de Bullock como las piezas No. 36 y No. 43, respectivamente. Es probable que el Códice Boturini exhibido no haya sido el original sino la copia que hizo Agostino Aglio. 
Segundo, que Bullock fue uno de los primeros inversionistas ingleses del México Independiente, al adquirir una mina de plata en Temascaltepec, la cual atendió de 1825, año en el que vende su colección mexicana y el Egyptian Hall, hasta 1827 cuando emigra a los Estados Unidos (Costeloe, 2010: 1208 a1211).

Tercero, que en el prefacio de un segundo catálogo de la muestra también aparecido en 1824, donde se presentaban las dos exposiciones de Ancient y Modern México, se hacía una clara alusión al papel anticipatorio que había tenido el coleccionista para el establecimiento de las relaciones comerciales entre México e Inglaterra, así como al papel protector de Gran Bretaña para asegurar la "felicidad de ambas naciones" (Bullock, 1824b, IV).

De este modo, es probable que Bullock, consciente de las fuerzas imperialistas inglesas, así como de los posibles planes de algunos sectores políticos mexicanos de fincar parte de la mexicaneidad en la cultura azteca, haya decidido hacer dos exposiciones: una dedicada al México antiguo y otro al moderno que anulaba per se al periodo colonial español.

A pesar de haber surgido en dos países diferentes, Ancient México y Aztec Show tuvieron varios puntos en común: En primera instancia, ambas exhibiciones estuvieron sustentadas por un relato de viaje que, a su vez, sirvió como herramienta de difusión y como texto explicativo/justificativo, lo que muestra la importancia que tuvieron los relatos de viaje en la representación y exhibición de la otredad.

En tanto narraciones centraron sus retóricas de veracidad en el papel del testigo ocular. Además, explicaban el origen y rasgos culturales de los "aztecas", a través de la influencia de otras civilizaciones como la egipcia (Ancient México) y la asiria (Aztec Show), lo que pone en evidencia una temprana aparición de las teorías difusionistas extremas como la postulada años después por Grafton Elliot Smith (1871-1937), quien sostenía que todas las culturas habían tenido un mismo origen: Egipto.

Por otro lado, retomando los tipos de argumentación señalados por Hayden White para la configuración de la imaginación histórica (White, 1973), tanto el catálogo de Ancient México como el relato de viaje que dio vida a The Aztec show presentan una explicación por trama basada en el romance. y una interpretación dualista de la historia, donde las dicotomías de "civilización antigua" versus 
"sociedad moderna", así como "monstruosidad" versus "normalidad" fueron centrales para representar lo "azteca"."

Por otro lado, aunque poco sabemos en qué consistió el espectáculo de Máximo y Bartola que le llegó al gran público. Su paso por las salas de exhibición, los estudios fotográficos, las sociedades científicas y las ediciones de los periódicos de la época han dejado una considerable información visual, en las cuales también se repite este tipo de imaginación histórica.

En sus primeras apariciones (fig. 4 y fig. 5), los niños aztecas frecuentemente fueron representados en ropajes reales no occidentales para subrayar un halo enigmático y exótico. Además, fueron mostrados en contraposición del hombre europeo, vestido a la usanza victoriana, para acentuar la dicotomía entre lo "antiguo" y lo "moderno", lo "primitivo" y lo "civilizado". Se exageró su diminuta estatura y cabeza, así como su nariz aguileña para subrayar su rareza biológica, lo que con el tiempo contribuyó a desarrollar un concepto de lo freak ${ }^{8}$ como un "tipo" de la comunidad extranjera (Bodgan, 1998: 6; Medina, 2011: 244).

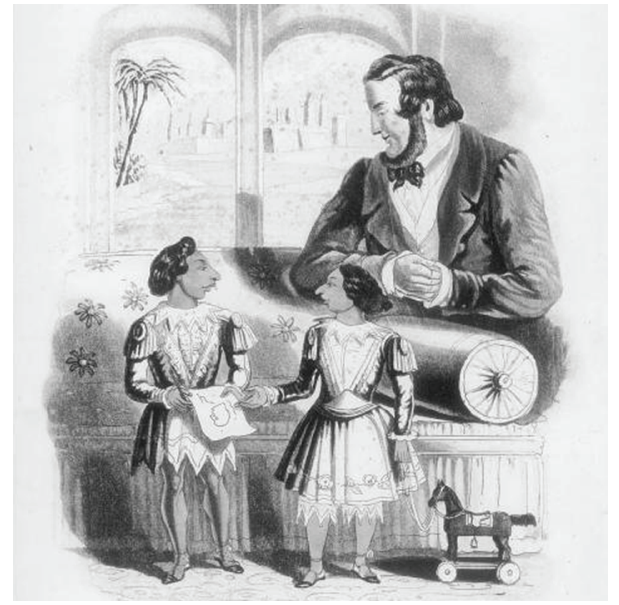

Fig. 4

7 Este tipo de argumento, que se caracteriza por mostrar a un héroe en un mundo ubicado entre el mito y lo real, con una historia centrada en la aventura y una estructura errabunda en forma de viaje o búsqueda donde puede participar lo maravilloso sin dejar de ser realista, se acentuaba en Memoir of an eventful expedition, donde tras librar una serie obstáculos, Pedro Velásquez lograba por fin "encontrar la ciudad perdida de Iximaya" y "rescatar" a los niños aztecas.

8 Fueron muchos los términos para denominar este tipo de personas con discapacidad o con rasgos extranjeros tales como rarezas, maravillas, monstruos, entre muchos otros. El término freak se introdujo a finales del siglo XIX. Por otro lado, este fenómeno se rastrea hasta 1810 con la exhibición de Sara Baarthan, mejor conocida como "Venus Hotentot", una mujer de la etnia nómada Khoikhoi, actualmente ubicada entre Namibia y Botswana, cuyas prominentes caderas fueron señaladas como distintivas de la tribu africana. 


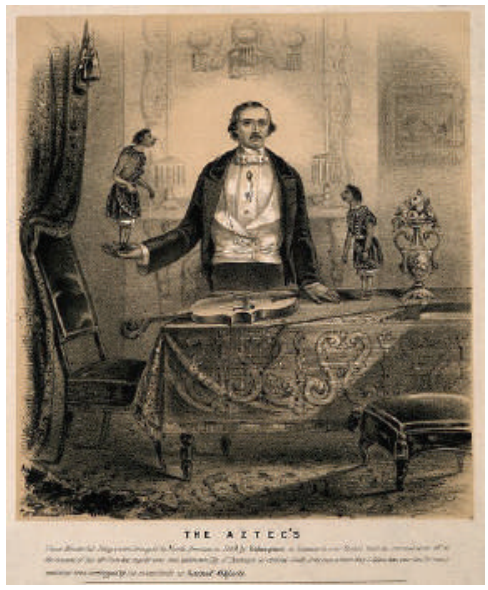

Fig. 5

Por otro lado, cuando el espectáculo The Aztec Lilliputians comenzó a decaer, se anunció el matrimonio de Máximo y Bartola, el cual se llevó a cabo en Londres el 7 de enero de 1867. Producto de este evento es la figura 6 en la cual se presentan ocho retratos ilustrados en los que se representa la historia de los niños aztecas, desde que son venerados en la mítica Iximaya hasta que contraen matrimonio. Este tipo de narraciones visuales también refleja una argumentación de tipo romance, donde el progreso triunfa.

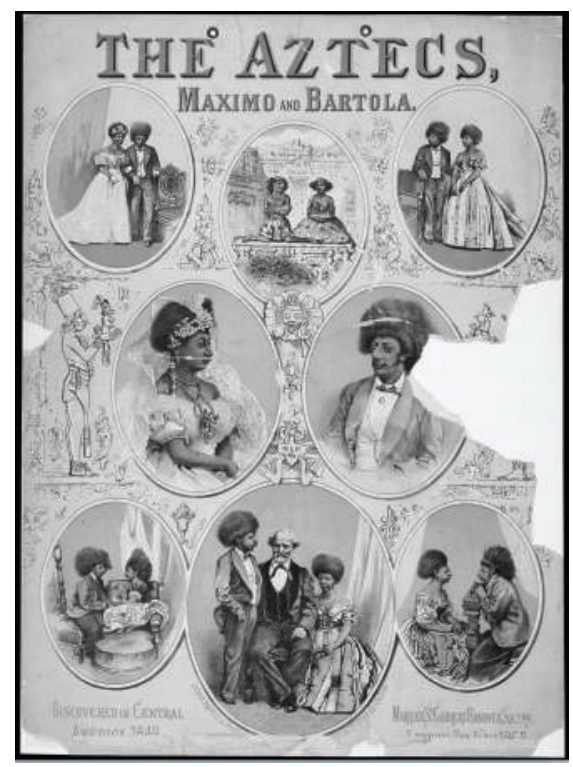

Fig. 6 
Finalmente, desde mediados del siglo XIX, Máximo y Bartola fueron retratados, ya sea en tarjetas de visita o en tarjetas de gabinete, formatos que popularizaron la fotografía como medio masivo de comunicación, modo de exhibición y fenómeno social pues las personas coleccionaban las tarjetas para verlas y comentarlas en reuniones. Ya que una de las características de este tipo de formatos fue la uniformidad de representación, aunque el fondo podía variar según la posición económica del retratado (Hannavy, 2008: 233 y 276), estas imágenes nos sirven para confrontarlas con los primeros grabados de Máximo y Bartola, y comprobar que muchos de sus rasgos físicos se exageraron para acentuar su representación como "raza única” y "rareza biológica" (fig. 7).

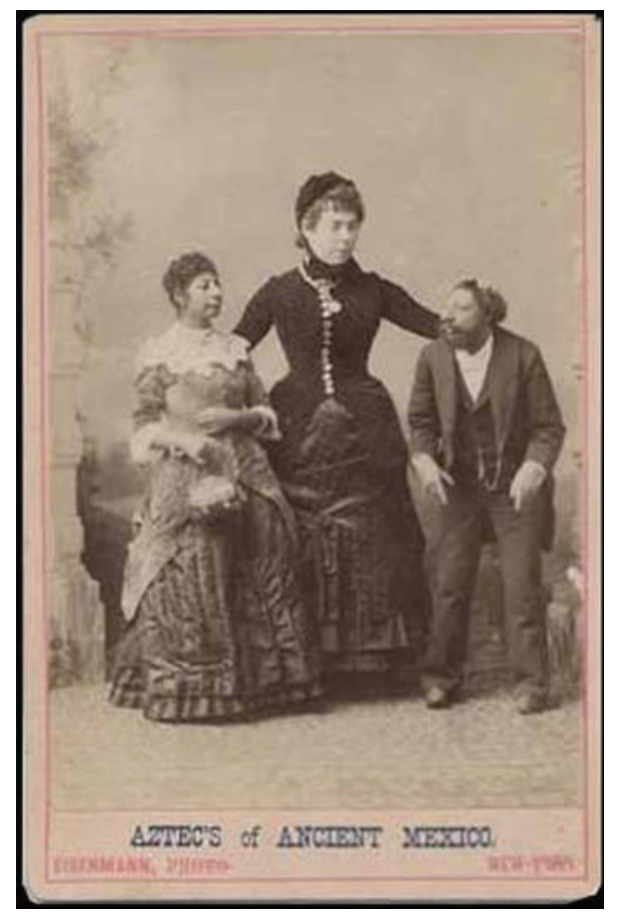

Fig. 7

Las últimas noticias e imágenes (fig. 8) que se conocen de Máximo y Bartola fueron publicadas por Rudolf Virchow en 1901 como parte de un artículo científico, cuando Bartola tenía aproximadamente 48 años y Máximo 53 pues, dada su condición física, su edad era difícil de determinar. Resulta significativo que en estas imágenes tomadas en los albores del siglo XX aparezcan desnudos como si el halo misterioso y exótico que los envolvió en el siglo anterior se hubiera desvanecido hasta convertirlos en meros objetos de estudio, lo que 
concuerda con la tesis de Aguirre de que Máximo y Bartola dejaron de ser un espectáculo de maravillas o rarezas humanas para, poco a poco, convertirse en la representación de la declinación del mestizo o del mulato, en comparación con la superioridad de la raza blanca europea (Aguirre, 2005).

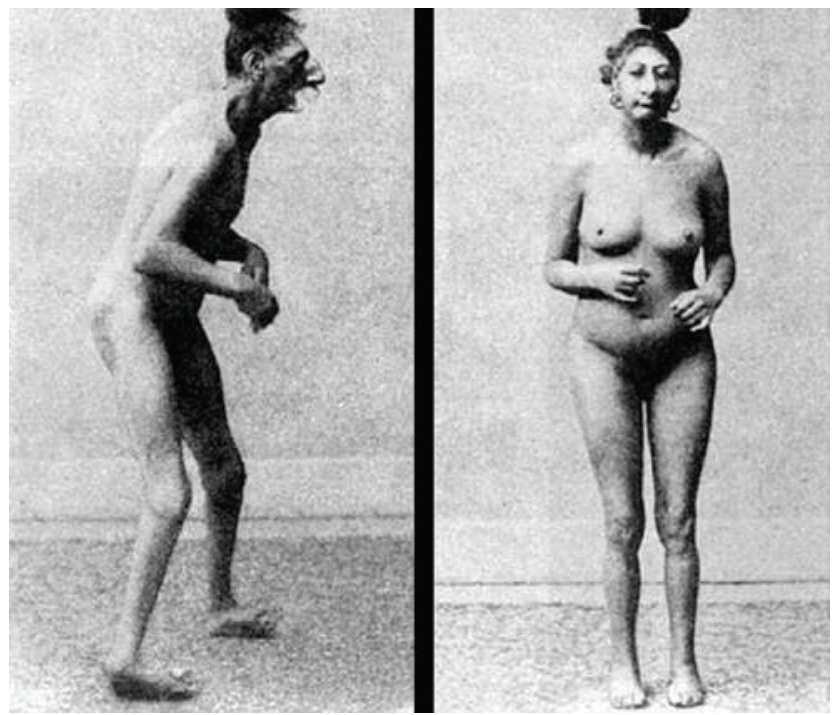

Fig. 8

HACIA UNAS CONCLUSIONES

A largo de este artículo he insistido en que hubo un tipo de exhibición del complejo expositivo del siglo XIX-ya sea exposición o espectáculo-que estuvo íntimamente relacionada con las prácticas y relatos de viaje: éstos fueron su punto de partida, y en ocasiones, su sustento o justificación. Tal es el caso de Ancient México y The Aztec Show que, a pesar de tener propósitos, formas de exhibición y objetos de exposición distintos, coincidieron en la forma de argumentar sus narraciones, en gran medida por estar basadas en prácticas y relatos de viaje, mediadas por visiones dualistas y difusionistas de la historia, por tramas argumentativas ligadas al romance y por estrategias de veracidad sustentadas en el testimonio, las cuales contribuyeron a generar en la sociedad inglesa de una gran parte del siglo XIX una noción de lo "azteca" ligada a las ideas de "civilización antigua", "ciudad perdida", "misterio" y "exoticidad".

Utilizando la terminología de Edward Said, este tipo de relatos y exhibiciones generaron ficciones de viaje, es decir, representaciones culturales de la otredad que, aunque sean convincentes para quien las emite, reflejan más su propia 
mirada que la realidad misma, y fomentan una actitud textual que influye en las futuras representaciones sobre dicho espacio.

Si bien no hay elementos que sugieran que Ancient México pudo haber influenciado directamente la creación del relato que dio sustento a The Aztec Show, principalmente porque la primera surgió en Inglaterra y la segunda, en Estados Unidos con 25 años de diferencia, considero que la exposición de Ancient México, además por supuesto de la publicación de Incidents of Travel... de Stephens y de las ilustraciones de Catherwood, facilitaron la recepción de The Aztec Show en Inglaterra, pues perfilaron una actitud textual y acrecentaron el interés de especialistas y del público general por las culturas precolombinas. Haya sido el empresario P. T. Barnum o no quien haya publicado Memoir of an eventful expedition... para justificar el supuesto origen mítico de Máximo y Bartola, el autor que lo escribió sabía perfectamente que el espectáculo viajaría a Europa y que se convertiría en un tema de discusión científica y de interés popular (Velásquez, 1850: 35).

No obstante, con ello no pretendo concluir que la recepción de ambas exhibiciones fue igual. En primera instancia, incluso en el siglo XXI obtener conclusiones acerca de la recepción de las exposiciones supone un reto metodológico que ni siquiera los estudios de público han podido resolver, pues en su mayoría están concentrados en obtener datos socio-económicos, a través de encuestas, en lugar de detectar y analizar formas de significación por medio de entrevistas a profundidad o de la sistematización de estudios de caso.

Por consiguiente, el estudio de la recepción ha quedado limitado al análisis de los medios de comunicación, en especial de la prensa escrita, bajo la premisa — quizá desmedida - de que rigen y engloban a la opinión pública. Bajo esa óptica limitada, la recepción de dichas exhibiciones fue diferente, en especial en cuanto a su veracidad. Por un lado, la prensa victoriana realizó una amplia cobertura de Ancient México, admitiéndola como verdad. En ocasiones, fue calificada como una colección de curiosidades o maravillas y en otras se señaló los vínculos entre México y Egipto. Por otro lado, desde su llegada a Londres, el caso de los aztecas liliputienses dividió a la opinión pública y a la comunidad científica e intelectual: periódicos como Boston Advertier, Boston Post (Medina, 2011: 253) y más adelante Illustrated Sporting and Theatrical News and Record of General and Domestic Intelligence consideraban que la historia era plausible mientras que otros periodistas, científicos e intelectuales dudaban de su veracidad, entre ellos Humboldt, quien le escribió un carta a J.M. Morris, entonces manager de Máximo y Bartola (Comas, 1968: 99-100).

Paradójicamente, este interés de comprobar su verdadero origen y de clasificarlos en una tipología racial contribuyó a que el fenómeno de Máximo y Bartola continuara intrigando a hombres de ciencia, audiencias y opinión 
pública hasta entrado el siglo XX. Después de todo, como se preguntaba el Illustrated Sporting and Theatrical News...:

\footnotetext{
“¿Quiénes son los liliputienses aztecas? ¿Son una gran verdad humana-una nueva página abierta en el Libro de la Vida que todos los niños de la humanidad deberán leer o son un fraude inteligente? La primera de esas preguntas puede ser respondida por profundos académicos, por los más eruditos filósofos (...). La segunda pregunta puede ser contestada en el momento: Ellos no pueden ser materia de fraude porque están aquí. Nosotros los tenemos frente a nosotros, palpablemente, carnalmente, substancialmente - en espíritu y en la verdad (Illustrated Sporting and Theatrical News.., 1867).
}

\section{BIBLIOGRAFÍA}

AguirRe, D. Robert. (2003), Exhibiting Degeneracy: The Aztec Children and the Ruins of Race en Victorian Review. Vol. 29, No.2. Invierno 2003, pp. 40-63.

AguirRe, D. Robert. (2005), Informal Empire:Mexico and Central America in Victorian Culture, Minneapolis: University of Minnesota Press.

Altick, Richard Daniel (1978), The Shows of London, Cambridge: Harvard University Press.

ANDREWs, Catherine. (2011), "Los primeros proyectos constitucionales en México y su influencia británica (1821-1836)", Mexican Studies/Estudios Mexicanos. Vol. 27, No. 1. Invierno 2011, University of California Press, pp. 5-43.

Bennett, Tony (1995), The Birth of the Museum: History, theory, politics, Londres y Nueva York: Routledge (versión libro electrónico).

Bluford, Adams. (1997). E. Pluribis Barnum: The Great Showman \& the Making of U.S., Popular Culture, Minneapolis: University of Minnesota Press.

Bogdan, Robert (1988), Freak Show: Presenting Human Oddities for Amusement and Profit, Chicago and London: The University Chicago Press.

Bogdan Robert, ELKS Martin, KNOLL James A (2012), Picturing Disability: Beggar, Freak, Citizen, and Other Photographic Rhetoric. Nueva York: University of Syracuse.

Bullock, William. (1824a), A description of the unique exhibition, called Ancient Mexico; collected on the spot in 1823 by the assistance of the Mexican Government and now open for public inspection at the Egyptian hall, Piccadilly. London, W. Bullock. Impreso por el propietario.

BuLlock, William. (1824b), A descriptive catalogue of the exhibition, entitled Ancient and Modern México: containing a panoramic view of the present city, specimens of the natural history of New Spain: models of its vegetable produce, habitations, 
costume, \&c. \&c.: and of the colossal and enormous idols, the great calendar and sacrificial stones, temples, pyramids, and other existing antique remains: the whole forming the rationally instructive and interesting exhibition, which is now open for public inspection, at the Egyptian Hall, Piccadilly. Londres: William Bullock. Impreso por el propietario.

Colombi, Beatriz. (2010). "El viaje, de la práctica al género", en Viaje y relato en Latinoamérica en Mónica Marinote y Gabriela Tineo (ed.), Buenos Aires: Katatay, p. 287-308.

Comas, Juan. (1968), Dos microcéfalos aztecas. Leyenda, Historia y Antropología. México: UNAM.

Costeloe, Michael P. (2010), "El panorama de México de Bullock/Burford, 18231864: historia de una pintura", Historia Mexicana, vol. LIX, núm. 4, abril-junio de 2010, pp.1205-1245.

Desvallées, André y MAIRESSE, François (dirección) (2010), Conceptos claves de museología, París: ICOM-Armand Colín.

DurbaCH, Nadja. (2010), Spectacle of Deformity: Freak Shows and Modern British Culture. Berkeley y Los Ángeles: University of California Press, 2010.

FerRater Mora, José. (1994), Diccionario de Filosofía, Tomo III, Barcelona: Editorial Ariel.

Hannavy, John, ed. (2008), Encyclopedia of Nineteenth-Century Photography, Nueva York y Abingdon: Routledge.

Illustrated Sporting and Theatrical News and Record of General and Domestic Intelligence. Sábado 16 de febrero de 1867.

LeJeUne, Philippe (1975), El pacto autobiográfico y otros estudios, Madrid: MegazulEndymion

Medina, Emma Isabel. (2011), Structuring the notion of 'ancient civilisation' through displays: semantic research on early to mid-nineteenth century British and American exhibitions of Mesoamerican cultures. Tesis de Doctorado, Instituto de Arqueología. Londrés: University College London.

Pearce, Susan. (2007), "William Bullock: inventing a visual lenguaje of objets" en Knell, Mcloed y Watson (ed), Museum Revolutions: How Museums Change and are Changed, Abingdon: Taylor\&Francis e-Library, pp. 15-27.

SAID, Edward (1997), Orientalismo, Segunda edición, 2002, Barcelona: Random House Mondadori.

QURESHI, Sadiah. (2011), Peoples on Parade: Exhibitions, Empire, and Anthropology in Nineteenth-century Britain. Chicago: University of Chicago Press. 
Velásquez, Pedro. (1850), Memoir of an eventful expedition in Central America; resulting in the discovery of the idolatrous city of Iximaya in a unexpected region and the possesion of two remarkable aztec children, descendants and specimens of the sacerdotal caste (now nearly extinct) of Ancient Aztec Founders of Ruined Temples of that Country described by John L. Stevens, Esq. and other travellers. Nueva York: Impreso por J. Bell.

Werner, Alex (2003) "Egypt in London. Public and Private Displays in the 19th Century Metropolis" en Humbert y Price (ed), Imhotep Today, London: University College London.

WHITE, Hayden (1973), Metahistoria. La imaginación histórica en la Europa del siglo XIX. Segunda edición, Quinta reimpresión, 2014, México: Fondo de Cultura Económica, 1992.

\section{TABLA DE IMÁGENES}

Fig. 1. Panfleto de The Aztec Show. c.1850 (Fuente: Cortesía del Museo de la Ciudad de Nueva York en Medina, 2011:242).

Fig.2. Ídolo partido en Copan. Ilustración de Frederick Catherwood (1844). (Fuente: http://www.casacatherwood.com/catherwoodencastellano.html).

Fig. 3. Litografía de Agostino Aglio de la exposición de Ancient México en el Egyptian-Hall ,1824. (Fuente: www.wikipedia.com).

Fig. 4. Portada de la partitura "The Aztec Polca" compuesto por W. West. que se vendió como souvenir durante el espectáculo The Aztec Lilliputians en Londres hacia 1853 (British Library en Durbach, 2010: 138).

Fig. 5 Dos personas miniatura conocidos como los Aztecas liliputienses, con su manager. Litografía de G. Wilkinson. s/f. (Fuente: Wellcome Library).

Fig. 6 Los aztecas: Máximo and Bartola. Descubiertos en América Central. Casados en St. Georges Hanover Square, Londres en 1867 (Fuente:Wellcome Library).

Fig 7. Tarjeta de gabinete de Máximo y Bartola tomada por Charles Eisemann s/f. (Fuente: https://noliquidificador.wordpress.com/2009/10/10/freak-maximoe-bartola-os-liliputianos-astecas).

Fig. 8. Fotografías de Máximo y Bartola, publicadas por Rudolf Virchow en 1901 (En Comas, 1968). 